\title{
RADIOGRAFIA DE UN CONTACTO: LOS NAHUA Y LA SOCIEDAD NACIONAL
}

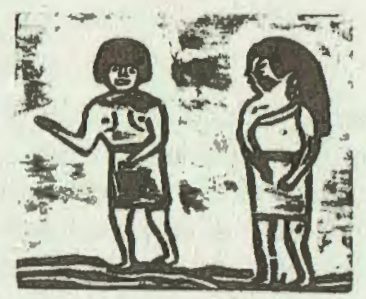

por: Alonso Zarzar*

This article is an attempt at a detailed reconstruction of one of the most recent processes of contact between a group of $P$ ano speakers (until recently iso. lated), inbabitants of the beadwaters of the Mishagua and Manu rivers, with different members of the regional society of the lower Urubamba and specially of the town of Sepabua. This article is also a first arialytical approach to the social conduct, the ethnic activities and the classification categories of the social universe involved in this process. Also, it tries to account for the social and cultural conformation of the of the social groups involved and the strategies of the institutions involved in this process.

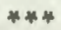

Le présent article tente de reconstruire de façon détaillée l' un des derniers processus de contact $d^{\prime}$ ' un groupe parlant Pano (il y a peu de temps encore dans lisolement) babitants des sources des affluents Mishagua et Manu, avec les divers membres composant la société de la région du Bajo Urubamba et notamment du village de Sepabua.

Mais cet article est aussi une premiére approximation analytique de la conduite sociale, des activités étbriques et des catégories de classification de l'univers social qui interviennent dans un tel processus.

De même il essaie de renche compte de lorganization sociale et culturelle des groupes sociaux concernés et des stratégies des institutions qui jouent un rôle ce processus.

\footnotetext{
* M. Phil en Antropología Social. Actualmente, candidato al Doctorado (Ph. D) en la Universidad de Cambridge, Ingla-
} terra. 


\title{
ANTECEDENTES
}

\begin{abstract}
"Qué contiene la civilización occidental que la bace infinitamente más etnocida que cualquier otra forma de sociedad? Su régimen de producción económico, jusiamente espacio de lo ilimitado, espacio sin lugares en cuanto que es negación constante de los limites, espacio infinito de una permanente huida bacia adelante". Pierre Clastres (1981)
\end{abstract}

Desde hace aproximadamente quince años que se tiene noticia de la existencia de una serie de pequeños grupos indígenas "Nahua", Pano hablantes (d'Ans 1972; Dourojeanni y Ponce 1978), habitantes de las cabeceras de los ríos Manu, Mishagua y Purús. Los misioneros Dominicanos de Sepahua señalan que hace treinta años los Amahuaca, en ese entonces habitantes del río Alto Sepahua, hablaban de ellos como de un grupo de "enanos". Ya en un mapa publicado por las misiones Dominicas en 1947 (Febrero, 1974; véase Mapa No. 1), se indican diversas aldeas en las cabeceras de los ríos mencionados, pero no se señala su pertenencia étnica. Esta zona está situada en el encuentro de los departamentos de Ucayali, Madre de Dios y Cuzco, y se encuentra parcialmente dentro del Parque Nacional del Manú (véase Mapa No. 3); quizá el último reducto (ecológico a la vez que cultural) que ha permanecido en relativo aislamiento, al menos en los últimos 80 años, desde la caída de la explotación cauchera en la región.

Entre los antecedentes más resaltantes al contacto definitivo, se registran los siguientes eventos:

En los años 1953 y 1955 los Nahua bajaban hasta la desembocadura del río Mishagua en el Urubamba, donde se producían enfrentamientos con los nativos de Sepahua; la misión había sido fundada ahí en 1947. En 1974, madereros provenientes de Atalaya (al norte de Sepahua) tienen un enfrentamiento con los Nahua en el río Mishagua, en el que algunos madereros son heridos. Posteriormente los madereros regresan, en plan de venganza, con veinte Campas que ocasionan varias muertes entre los Nahua. Hacia fines de 1976 los misioneros Dominicos llevan a cabo una expedición al río Pakiria (afluente del Urubamba (véase Mapa No. 1), con el objetivo de conectar a los Kogapakoris o Machiguengas aislados. En conversaciones con los Machiguengas, estos les confirman la existencia de los Nahua en el Alto Serjali (brazo principal del río Mishagua, véase Mapa No. 2), a quienes consideran sus enemigos (Las Heras, 1977).

Como años después confirmariamos, en el Serjali han habido enfrentamientos entre ambos grupos; los Machiguengas dejaron este río hace pocos años. A comienzos de 1977 los misioneros Dominicos denuncian una correría realizada por madere- 
MAPA 1

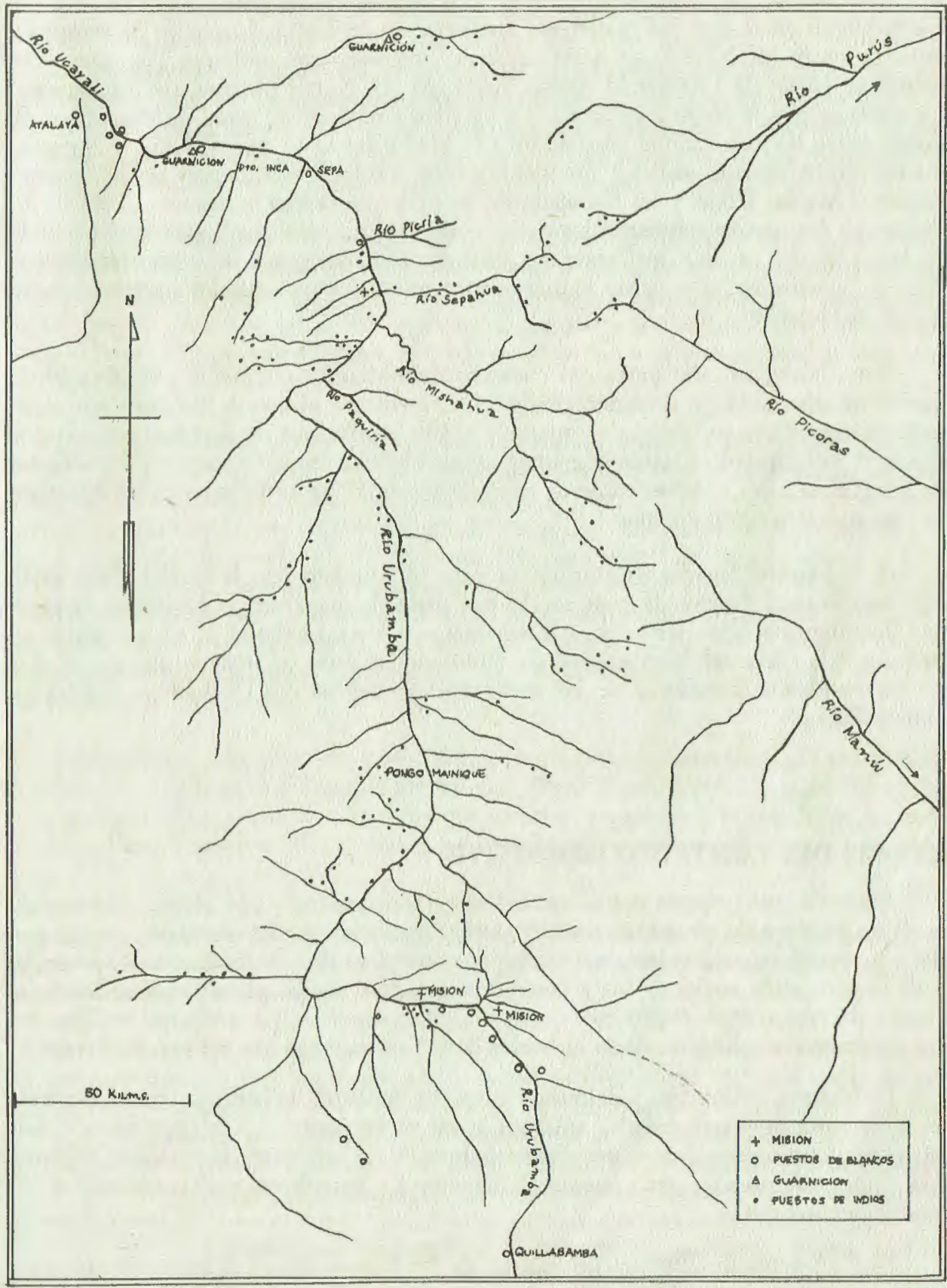

Fuente: Fr. Andrés Ferrero, 1947.

Digitalizado en el CENDOC- CAAAP 
ros de Sepahua contra los Nahua en el Alto Mishagua. En 1981 hay un nuevo enfrentamiento en el que dos madereros son heridos, se ignora el número de heridos o muertos entre los Nahua. En 1983, durante una visita del entonces Presidente Belaúnde al Istmo de Fitzcarrald (véase Mapa No. 3), con el objetivo de inspeccionar los trabajos que la Marina venía realizando para construir un canal de interconexión fluvial entre las cuencas del Urubamba y el Madre de Dios, se produjo un enfrentamiento entre nativos aislados no identificados, probablemente uno de los grupos Nahua o Machiguenga, y los trabajadores. Noticia que pasó a la primera plana de los diarios en los que se referían a los nativos como "Piro-Mashcos", gentilicio acuñado en la época del caucho, que, para los Piro actuales, designa a los Piro "no civilizados" o "guerreros", que ya no existen sino como fantasmas sociales y representaciones de carácter mítico.

Por último, un año antes del contacto definitivo, la compañía petrolera Shell, que viene operando en la región desde 1981, mediante el uso de helicópteros obsequia machetes que son arrojados mientras el jefe Yaminahua de Sepahua perifoneaba desde el helicóptero. Táctica que tenía como objetivo impedir mayores incursiones de los Nahua a los campamentos de explotación en el Alto Mishagua, para agenciarse esas preciadas herramientas.

Así, durante décadas este grupo se negó al contacto con la sociedad nacional, rechazando todo intento de penetración por parte de madereros y petroleros, a quienes sustraían machetes y hachas, o previamente a los misioneros de no proseguir en su búsqueda; pero también huyendo e internándose cada vez más en las zonas altas de los pequeños tributarios de las tres grandes cuencas del Urubamba, Madre de Dios y Purús.

\section{ETAPAS DEL CONTACTO DEFINITIVO}

Parto de una premisa que es también una constatación: todo proceso de contacto es un proceso de etnocidio, incluso a veces inconciente e involuntario, y cuyo grado y profundidad dependen de un conjunto complejo de circunstancias y estrategias y de la naturaleza social de los grupos interactuantes. En lo que sigue procuraré dar cuenta de este complejo proceso, cuyos múltiples aspectos, sin embargo, no pueden ser totalmente explicados, dado el hecho de ser un proceso iniciado recientemente.

La historia del último y definitivo contacto, recuerda la historia contemporánea de la mayoría de las sociedades amazónicas en su encuentro con el mundo occidental; pero tiene características peculiares dado que, en este caso, la sociedad regional está compuesta no sólo por misioneros, madereros y petroleros, sino también por comunidades nativas.

Será en mayo de 1984 que el destino de los Nahua sufrirá el inicio de una serie de cambios dramáticos. El campamento de un grupo de madereros en el Alto Misha- 
gua, entre los que se encontraban Machiguengas, Yaminahuas y mestizos de Sepahua y Nueva Luz (asentamientos en el Bajo Urubamba, véase Mapa No. 2), es asaltado por los Nahua que se habían hecho de algunas herramientas. Los madereros irán en su búsqueda, pero en los esporádicos enfrentamientos no hay muertos ni heridos que lamentar. Al día siguiente, los Nahua son sorprendidos durmiendo y llevados maniatados al pueblo de Sepahua; la presencia de un Yaminahua entre los madereros y por ende la posibilidad de comunicación, evitó un desenlace sangriento.

Al llegar a Sepahua son alojados por el jefe de la comunidad Yaminahua durante algunos días. La misión, la compañía petrolera y los propios habitantes de Sepahua les entregan ropa vieja y herramientas usadas. Posteriormente el jefe Yaminahua los regresa a su territorio, pero sin llegar hasta sus aldeas. Este informante confesó haber sentido miedo y por eso sólo los llevó hasta el brazo Serjali (véase Mapa No. 2).

En Junio del mismo año, cuatro hombres Nahua, entre los que se cuentan dos de los que fueron capturados, llegan a Sepahua habiendo establecido voluntariamente contacto con un deslizador con personal de la Shell y son alojados nuevamente por el jefe Yaminahua de Sepahua, período en el que contraerán el virus gripal. En esos días aterriza una avioneta del Instituto Lingüístico de Verano a solicitud del director del Hospital Amazónico y entran en contacto con los Nahua. El ILV sabía de la existencia de los Nahua pues desde 1981 tiene permiso del Ministerio de Educación para desarrollar sus actividades entre esta población. Los Nahua son llevados a la comunidad Machiguenga de Nueva Luz, donde miembros del ILV inician un estudio preliminar del idioma.

Producido el contagio, son aconsejados, de regresar lentamente hacia sus aldeas, después de recibir parcial tratamiento médico. Pero el jefe Yaminahua de Sepahua, encargado de llevarlos, no se tomó las dos semanas sugeridas e hizo el viaje en cuatro días. Posteriormente el ILV envía dos lingüistas con quienes él regresa por unos dias.

Así es como entre Junio y Agosto de 1984 se desata una epidemia de gripe que rápidamente derivó en neumonía y puso en peligro de muerte a todos los grupos lo. cales Nahua contactados hasta entonces.

En los primeros días de agosto el ILV envía un equipo compuesto por un médico, una enfermera y dos linguistas. La situación es dramática: 130 enfermos, de los cuales mueren entre 40 y 60 . Con el apoyo de Amahuacas y Yaminahuas de Sepahua, el ILV realiza dos campañas de vacunación a la par que establece su puesto a un día de camino de la aldea más próxima. Durante ocho semanas logran atender cerca de 200 personas provenientes de diferentes aldeas. Los Nahua se mostraron afectuosos y en su desesperación por curarse, pedían ser inyectados varias veces e intentaban usar las hipodérmicas descartables. Solicitan ollas, machetes, hachas y chaquiras que los miembros del ILV intercambian por cinturones de dientes de mono y collares de semillas. 
MAPA 2

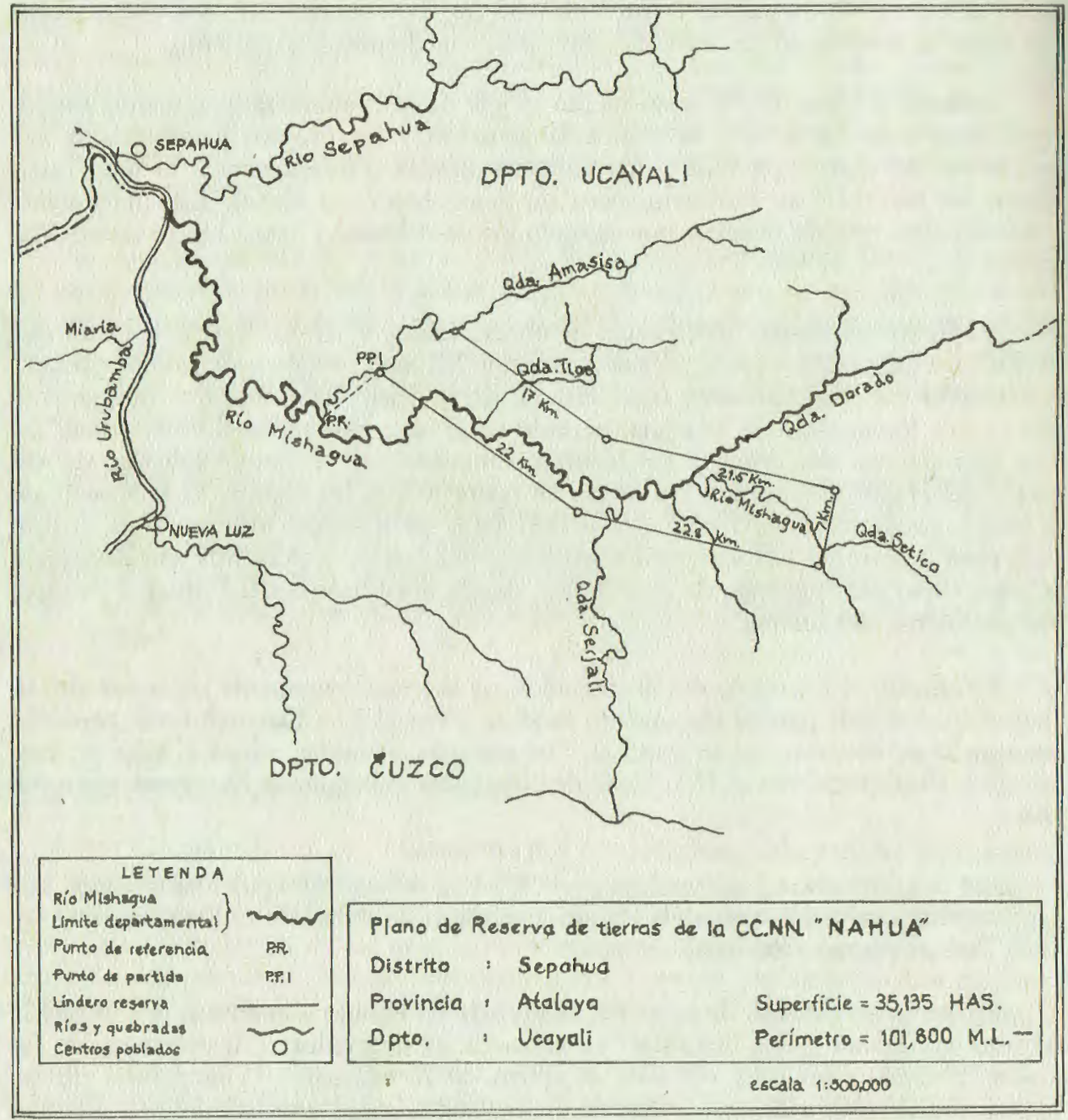

Fuente: Ministerio de Agricultura. Pucallpa, 1985. 
Después de siete meses de atención médica interrumpida por intervalos de varias semanas, la epidemia logró ser parcialmente controlada.

En este período el jefe Yaminahua de Sepahua, demostró ser un eficaz mediador cultural y comenzó a adquirir una'propia e independiente manera de interactuar con los Nahua. Finalmente ganó su total confianza y es considerado por los Nahuas como un poderoso curandero, un hábil cazador y un hombre que conoce el mundo de afuera.

Durante este período, la forma de vida de los Nahua se vió totalmente alterada. Estando muy enfermos e incapacitados para cazar devinieron completamente dependientes de los Yaminahua para obtener fuentes proteícas, y de los miembros del ILV por el apoyo médico. Cerca de ochenta Nahuas se trasladaron río abajo hasta el puesto del ILV, pero se vieron forzados a regresar a sus aldeas (a un día de camino) varias veces por semana, para recolectar alimentos de sus viejas chacras, dado que en el puesto del IIV no habían productos agrícolas.

Esta situación duró hasta Julio de 1985, cuando los Nahua -a sugerencia del jefe Yaminahua, y dado casi el total agotamiento de sus chacras- deciden asentarse en Sepahua.

Esta decisión no fue considerada con detenimiento y fue tomada más bien en medio de la desesperación. Al menos de algo estaban seguros los Nahua: no querían regresar a vivir en sus aldeas pues mucha gente había muerto ahí. Finalmente se vieron atraídos tanto por Sepahua, que ellos veían como un paraíso de bienes manufacturados, como por el poder de convencimiento de los Yaminahua que les ofrecieron su apoyo para asentarse.

Sin embargo, pocas semanas después de estar en Sepahua y una vez que la exitación de experimentar un ambiente totalmente distinto y nuevo había pasado, los Nahuas se dieron cuenta que la imagen presentada por los Yaminahua no era muy exacta y que Sepahua no era un lugar fácil para vivir.

Por su parte los Yaminahua se percataron de las dificultades que acarreaba el hecho de doblar su población de la noche a la mañana. La escasez de alimentos y la carencia de techo fueron problemas prácticos que tuvieron que enfrentar.

Por un tiempo, los Nahua continuaron indecisos de permanecer en Sepahua y andaban por el pueblo mendigando comida de otras familias nativas; pero finalmente decidieron establecerse en Sepahua y algunos comenzaron a construir pequeñas casas y a hacer nuevas chacras. En este período los miembros del ILV también se trasladaron a Sepahua.

Esta situación se prolongó sin mayores ni sustantivos cambios hasta agosto de 1986, cuando una parte de los Nahua -en número de cincuenta, aproximadamenite retornaron al río Mishagua por sugerencia de los miembros del ILV; quedando en 
Sepahua aproximadamente treinta de ellos. Aunque esto está por ser confirmado, es posible suponer que el grupo que retornó al Mishagua haya sido el que está bajo influencia del líder mayor de los Nahua, quien en ocasiones señaló no sentirse bien del trato que recibían de los pobladores de Sepahua. El joven líder (en realidad un chamán), más bien se inclinaba por establecerse en Sepahua y no deseaba participar en nuevos y probables traslados.

\section{CLASIFICACIONES LINGUISTICAS, IDENTIDADES ETNICAS Y NATURALEZA DE LOS GRUPOS INDIGENAS}

Según la clasificación lingüística más acabada sobre esta área cultural (d'Ans 1973), los Nahua forman parte de un conjunto de grupos o subunidad lingüística dentro de la familia Pano, los Pano del sudeste que se dividen en: Amahuacas, Cashinahuas y Pano-Purús. Toda la formación indica que los Nahua son parte de esta última división Pano-Purús junto con los Yaminahua, Sharanahua, Marinahua, Mastanahua y Chandinahua.

Nahua es un gentilicio que en Sharanahua y en Shipibo y en un contexto de interacción y clasificación de los "otros", significa "foráneo", "extraño" y designa al "otro", al no pariente, enemigo y/o aliado potencial. En la escasísima literatura existente sobre los Nahua específicos, estos han sido llamados Equis-Nahua (X-Nahua) por desconocerse otra denominación (Dourojeanni y Ponce 1978) y Parque Nahua según el ILV, por su ubicación colindante con el Parque Nacional del Sanú.

Los calificadores étnicos son construcciones conceptuales que se producen en un conjunto de relaciones entre diversos grupos sociales, sean estos indigenas y/o sectores de la sociedad envolvente. Elnombre étnico es una elaboración categorial cuya función es marcar la deferencia y posibilitar la identidad a la vez que genera un campo semántico que constituye una de las áreas más relevantes de los modelos folk del universo social.

Para los misioneros Dominicos y los Yaminahua de Sepahua, los Nahua son Yaminahua. Estos últimos se comunican con los Nahua sin dificultades, aunque reconocen la existencia de variaciones fonéticas. Ellos los llaman también Chochonahua, "gente de pechos grandes"; sobrenombre congruente con el significado de otros etnónimos Nahua que también se refieren a atributos físicos y naturales.

Los Yaminahua dividen a los grupos Nahua en dos conjuntos, y de acuerdo con criterios que tienen que ver con niveles de comunicación y entendimiento del idioma hablado por los otros:

a) Yaminahua, Sharanahua y Marinahua que hablarian la misma lengua, junto con los Nahua recién contactados y b) Chandinahua, Mastanahua, Chosinahua y Cashinahua que hablarian una lengua distinta (Zarzar, 1977-78). 
Clasificación que guarda algunas semejanzas con la señalada al inicio, desarrollada por d'Ans. Los Yaminahua del río Huacapishtea sostienen que anteriores generaciones de Yaminahuas habitaban la actual región de los Nahua. Los Amahuaca del río Bajo Pariamamú en Madre de Dios, dividen a los Yaminahua en Cashinahua y Shishinahua y consideran que los Marinahua no son parte de los Yaminahua (d'Ans 1972). Por su parte los Piro de Sepahua piensan que los Nahua no son 'legítimos' Yaminahua pues consideran que son demasiado bajos y creen que son Sharanahuas. Los mestizos y patrones madereros de Sepahua designa a los Nahua como 'los Shara' - 'Yami-Shara'. Shara es una palabra Pano de uso frecuente entre los Nahua que significa 'bueno', 'lo que está bien' y de donde se sigue el etnónimo Sharanahua. Los miembros del ILV consideran que el idioma de los Nahua está entre el Sharanahua y el Yaminahua, afirmación que coincide parcialmente con la clasificación de d'Ans y con la de los Yaminahua de Sepahua, y sostienen que hay por lo menos dos dialectos entre los Nahua.

Según Kensinger $(1983,860)$ "las lenguas Sharanahua y Marinahua son mutuamente inteligibles. No se sabe con exactitud si el Mastanahua, Chandinahua y Yaminahua son también mutuamente inteligibles, o si comparten ese rasgo con el Sharanahua y el Marinahua". Agrega que todavía no se aclara si el Yaminahua es o no un grupo lingüístico distinto o si está estrechamente emparentado con, o forma parte de, los Mastanahua y Chandinahua encontrados entre los Sharanahua de Purús. Sin embargo, los Amahuaca, Cashinahua, Sharanahua y Shipibo-Conibo se refieren a ellos como grupos separados. Esta últíma afirmación nos lleva a pensar que Kensinger confunde las semejanzas lingüísticas con el campo conceptual y simbólico de las identidades étnicas. Como señaló nuestro principal informante Yaminahua: 'estos nombres son para poder identificar a la gente'. Por otra parte, un líder Sharanahua llevado al Alto Mishagua por el ILV, constató la existencia de variaciones fonéticas entre los Nahua, coincidiendo con el jefe Yaminahua de Sepahua que afirma la existencia de Mastanahua conviviendo con los Nahua. Según el líder Sharanahua para él era más fácil entender el Yaminahua que el idioma de los Nahua y le era más fácil entender a los Nahua que hacerse entender por ellos.

Esta secuela de datos nos devuelve al punto de partida de la clasificación hecha por d'Ans: los Nahua hablarían un idioma afín al Yaminahua, Sharanahua, Mastanahua y Chandinahua, pero diferente al Cashinahua y al Amahuaca. Intentaremos aclarar esta selva lingüística recurriendo a algunas hipótesis sobre el origen y naturaleza de los grupos sociales que están tras estas clasificaciones.

Según Siskind (1973), nombres como Sharanahua, Yaminahua, etc., habrian sido tradicionalmente usados para referirse a las 'mitades' de los linajes. Hoy en día estos nombres, que se heredan por línea paterna, no se refieren a ningún grupo cohesivo en gran escala. Así, mientras los Cashinahua si hablan un idioma distinto, los Sharanahua no son sino un grupo de parientes que comparten un nombre, pero hablan el mismo idioma, aunque con variaciones locales, que otros pequeños grupos de parientes. Los grupos Pano-Purús son descendientes de poblaciones que compartían un mismo idioma. Con el transcurrir de miles de años, los idiomas fueron cambiando por efecto de las fisiones y las migraciones. 
En la misma linea de ideas, Townsley (1983) considera que los Yaminahua formaban parte de un gran número de grupos estrechamente relacionados entre sí y piensa que sería un error considerarlos como grupos étnicos. Siguiendo a d'Ans y Siskind, piensa que se trata de grupos lingüísticos que hablan un único idioma con diferencias dialectales, representadas por las comunidades que los conforman. Estos autores sostienen que es posible establecer patrones socio-culturales comunes sobre los Pano del bosque, aunque referidos a una época anterior a la traumática devastación cauchera: la conformación de pequeñas comunidades constituídas por malocas, políticamente autónomas y con un alto grado de endogamia. El nombre Yaminahua no designaría una unidad socio-política, sino una variedad de grupos que hablan idiomas similares. En la actualidad, período post cauchero, el complejo sistema de relaciones intergrupales se ha reducido a su minima expresión como colofón a la dispersión, fragmentación y recombinación de los anteriores grupos en nuevas unidades socio-culturales.

Para explotar la identidad étnica no es suficiente con cotejar clasificaciones lingüísticas, sino que es necesario, entre otros aspectos, penetrar en el campo semántico que despliega el nombre grupal: campo minado de referentes sociales, históricos, naturales y simbólicos.

El término 'Nahua', cuya variación es 'dwa', es usado por los Sharanahua y Yaminahua para designar a miembros de una de sus dos mitades exogámicas, pero también y en otros contextos, para referirse a grupos indígenas fuera de la familia Pano, como los Machiguengas, Piros, Campas y Culinas, e incluso para designar al peruano, mestizo o blanco (1). Su significado mítico más evocativo señala a aquellas 'gentes no humanas' que son percibidas como espíritus cazadores, habitantes del bosque, deseosos de carne humana. En ese conjunto están esos "otros" que desde el punto de vista mítico Nahua no se conforman a un patrón social humano, que son "caníbales, incestuosos y tienen un apetito sexual descomedido" (Siskind, 1973). La visión Pano de los Arawak y posteriormente de los blancos, tiene un transformo histórico tradicional de relaciones de dominación, guerra, servilismo y asimilación cultural, en la que los habitantes de tierra firme llevaron la peor parte (Zarzar, 1983). Visión que por otra parte, condensa esa historia. Una de las diferencias básicas se establece por la oposición humano/no humano, siendo el primer polo el mundo social Yaminahua - Sharanahua y el segundo, los grupos Arawak antes mencionados, agrupados con las criaturas sobrenaturales y demonios que habiten el bosque.

Al interior del mundo nahua existe otra incisión: los otros Nahua son 'otra gente' (yura wutza), los no parientes. Término que tiene como significado arcaico el de hermano entre los Sharanahua (Siskind, 1973). Indice de que antiguamente estos grupos conformaban una sola unidad socio-polírica. Hoy en día, mediante otra categoría, se incluyen a los otros grupos Nahua junto con los parientes.

(1) Los Yaminagua se denominan así mismos, 'odi-koi' (la verdadera gente) y llaman a los "otros" los 'odi-koiba" (Townsley, 1968). 
Los Yaminahua de Sepahua, en cuya comunidad hay varios mestizos casados con mujeres Yaminahua, designan a estos como 'dawa'. A diferencia de la oposición humano/no humano, los términos aplicados a los grupos Nahua tienen, al entender de los Yaminahua, los siguientes significados literales, esto es, de manera descontextualizada, como los significados que nos provee el diccionario:

$\begin{array}{ll}\text { Cashinahua } & \text { gente murciélago, que come murciélago o gente ratón calvo. } \\ \text { Chandinahua } & : \text { gente mentirosa. } \\ \text { Mastanahua } & : \text { gente enana, achatada (2). } \\ \text { Marinahua } & : \text { gente añuje, que come yuca verde como el añuje. } \\ \text { Sharanahua } & : \text { gente buena, hospitalaria y generosa. }\end{array}$

Esta clasificación indígena del universo social Nahua, que ha sido formalmente adoptada por la sociedad nacional y por el Estado, combina atributos físicos y/o naturales y cualidades culturales. Pero, a diferencia de la categoría 'dawa', estos grupos no son considerados 'no humanos'; son en todo caso humanos imperfectos, que pueden entrar en conflicto con las normas sociales locales sin llegar a violentar la cultura. Las características pseudo o para totémicas de estas clasificaciones yacen en el evidente carácter ilusorio de las cualidades atribuídas a los otros. Persisténtemente, aquello que se dice del otro es a todas luces inverosímil, pero su estatuto de verdad no es pertinente, sino la función diferenciadora que realizan. Lo que se dice del otro no es cierto, pero ese decir es condición de posibilidad de un 'nosotros'. Son estas más bien sociedades homogéneas, que establecen procesos de diferenciación con fines identificatorios. Como bien señala Schwartz (1981), la actitud totémica, aún cuando estas clasificaciones no sean tales, es una actitud etnizante: genera un conjunto de similitudes y oposiciones que hacen posible un panorama de identidades contrapuestas. Este ejercicio de metáforas, analogias y oposiciones, contribuye a quebrar el ecuménico prejuicio etnocéntrico, ensanchado y superando una identidad, para establecer en un plano menos manifiesto un universo donde los 'otros' no son excluidos sino incorporados en una clasificación del mundo cultural, y cuya presencia aparece como imprescindible para fundar una identidad propia.

Si entrásemos a describir la clasificación Amahuaca del mundo social, encontraríamos términos semejantes referidos a divisiones sociales al interior de la propia etnia. Estos gentilicios tienen un referente geográfico, determinado por un río, sus afluentes o encuentros de dos ríos. Tal vez un índice de que estas secciones fueron en el pasado grupos de descendencia territorialmente diferenciados y entre los cuales se establecían relaciones de guerra y alianza. Indice que guarda coherencia con la información histórica disponible y la tradición oral. Estos etnónimos nos indican, por otra parte, que estariamos frente a dos universos sociales: 1) Los grupos Nahua, incluídos los Cashinahua, y 2) los grupos Arawak-Piro, Culina, Machiguenga -a los que se asocian los blancos y mestizos bajo la categoria "dawa". Cabe aclarar, y esto es muy<importante, que estos nombres no se refieren necesariamente a grupos étni-

(2) Es significativo recordar que los Amahuaca consideraban as! a los Nahua. 
cos. Estas identidades no tienen siempre y en todo lugar como objeto de referencia un grupo étnico; en vez, este puede ser simplemente un grupo de descendencia con determinadas reglas de residencia y matrimonio; sin llegar a constituir el referente social de una identidad otra o étnica.

Veámos ahora la actitud nativa y mestiza de los habitantes de Sepahua sobre los Nahua. Para situar mejor sus campos de recepción y sus elaboraciones conceptuales, es necesaria una introducción al contexto social regional.

\section{EL CONTEXTO REGIONAL Y LOS FRENTES DE EXPANSION}

Sepahua, en tanto que pueblo-frontera o puesto de avanzada, ha sido central en el proceso de contacto con los Nahua. Se encuentra en la conjunción de los ríos Bajo Urubamba y Sepahua - a cuatro o cinco días de embarcación del Alto Mishagua, zona de los Nahua- y se caracteriza por su complejidad multiétnica y por los varios frentes socio-económicos e 'ideológicos' que ahí se han instalado. Fue fundado como misión por los Dominicos en 1947; a comienzos de siglo fue el centro cauchero de comercio más importante del sur de la selva y hoy en día es un distrito. Su población actual bordea los dos mil habitantes, no obstante casi la mitad es población flotante que se ha establecido en los últimos cinco años como parte del mercado de trabajo de la compañía petrolera que viene operando en la región con sede en Sepahua (3).. Su población indígena está compuesta básicamente por Piros, Amahuacas y Yaminahuas - que conforman la Comunidad Nativa de Sepahua- y por otro lado, por mestizos y blancos (misioneros y técnicos de Shell). Además de sus actividades tradicionales de subsistencia, la población nativa se dedica a la extracción eventual de madera y a trabajar ocasionalmente para la empresa petrolera; combinando su agricultura con cultivos comerciales como: cacao y frejol. Mientras que los llamados mestizos o afuerinos, se dedican en mayoría a la extracción forestal, a trabajar como asalariados en las empresas contratistas de Shell, y al comercio.

La región del bajo Urubamba y afluentes, ha venido siendo intensamente explotada con fines de extracción de madera, desde hace dos décadas (Zarzar, 1980). En el último lustro la actividad forestal decayó notablemente, menos por el agotamiento de recursos en las zonas de fácil acceso, que por la crisis económica que disminuyó el acceso a los créditos $-y$ con ella la población afuerina de Sepahua. Sin embargo, con la exploración petrolera, esta población se incrementó nuevamente.

El río Mishagua era el último reducto que quedaba por explorar en la región comprendida por el río Picria al norte y el Pakiria al sur (véase Mapa No. 1), zona de extracción maderera para la población de Sepahua. La virginidad de este territorio caló hondo en la imaginación de los Sepahuinos, incluídos los nativos, que veían en el Mishagua una suerte de "El Dorado" forestal; paraíso del cedro y la caoba. Algunos mestizos, en un derroche de fantasía, creían que los Nahua eran cerca de tres 
mil, y opinaban que con el ingreso del ILV estos se "pacificarían", de lo que se deducía que podían ser fácilmente incorporables a la explotación forestal como fuerza de trabajo barata o casi gratuita, dada su ignorancia del funcionamiento del mercado. Sin embargo, hasta el presente han llevado a cabo la explotación de la zona utilizando sus habituales peones, los nativos de Sepahua, a pesar de la orden de intangibilidad del área, decretada por el prefecto de la provincia, primero, y de la declaración de reserva de tierras dada por el Ministerio de Agricultura después (véase Mapa No. 2). Al respecto, es significativa la diferencia en el número de licencias forestales otorgadas entre los períodos 1978-82 y 1983-85 para la zona de Mishagua. En el primero se solicitaron 12 licencias y en el segundo estas aumentaron a 22. Es importante señalar que contextualmente la presencia de la exploración petrolera en la región y especialmente el hecho que los trabajadores petroleros trabajen incluso cerca de las cabeceras de afluentes, contribuyó al sentimiento entre los Sepahuinos de que el río Mishagua había sido, finalmente, abierto a la "civilización". La presencia del ILV terminó por fortalecer este sentimiento.

Para los madereros mestizos, tanto patrones como peones, los Nahua son el estereotipo del guerrero salvaje. Se refieren a ellos, no sin cierto desprecio, como gente "chúcara", "los calatos", y ven en éstos a simples criminales que han empezado a arrepentirse - al aceptar relacionarse- de las ocasionales muertes asestadas a algunos madereros que osaron penetrar al Alto Mishagua en años pasados.

Por su parte, los Piro consideran a los Nahua, como 'gente de monte' que no rozan donde habitan y viven bajo la sombra de los árboles; sociedad en la que el principio de reciprocidad y las normas del parentesco en la distribución de los bienes son inexistentes: un mundo supuestamente no solidario, en el que la cocina se encuentra en un estado incipiente, pues aseguran que comen sus alimentos, incluído el pescado, casi crudos. Su visión se encuentra además como tensada por una mezcla de temor inocultable con actitudes despectivas.

En este contexto destacan el rol, las actitudes, expectativas y estrategia del jefe Yaminahua de Sepahua en sus relaciones con los Nahua. Hombre entre dos mundos, intermediario en todos los niveles y ámbitos de relación: desde su trato directo con los Nahua, pasando por sus concepciones y actitudes éticas, hasta su constitución psicológica. Durante las dos primeras etapas de atención médica, su gran ayuda y sacrificio fueron resaltables, hechos que denotan una gran identificación humana, A ojos de los Nahua aparece como un 'padre salvador', lo llaman 'epa' -incluso los mayores - término que designa al padre clasificatorio. Desde los primeros contactos estableció alianza con una de las hijas de uno de los jefes de familia e hizo un claro en una de las aldeas, pretendiendo sirva para atraer a alguno de los helicópteros de la Shell. Posteriormente ingresó a la zona apoyado económicamente por un patrón de Sepahua con el objetivo de extraer madera y agenciarse peones gratuitos entre los Nahua. Se comunica muy bien con ellos y es ahora un pariente afín.

Su actitud es ambigua: intermediario, 'patroncito' y 'padre protector', generoso en la ayuda, pero deseoso de sacar provecho en su propio beneficio. Al igual que 
otros habitantes de Sepahua, percibe a los Nahua como gente lindante con el reino animal, marcando en esta percepción su gran movilidad y su patrón disperso de asentamiento: "viven pues como animales, aquí, allá, andando de un lado a otro". Al sostener que los Nahua son Yaminahua, estos Yaminahuas no pueden ocultar cierta vergüenza. La identificación con el salvaje les resulta problemática, pues es a la vez identificación con sus ancestros y su pasado más reciente; mundo del cual los Yaminahua han empezado a salir en un proceso de incorporación, agónico y desigual a la vida de un pueblo como Sepahua.

En el contacto se produce una confrontación entre dos modelos sociales folk y entre dos conjuntos categoriales: la sociedad nacional que en este contexto está marcada por su carácter sedentario y nucleado, por su relación técnica y pragmática con la naturaleza y cuya concreación paradigmática es la compañía petrolera; versus la sociedad primitiva marcada por su nomadismo, su dispersión, su ser para la guerra y su reducida cultura material y cuyo epítome lo representan los Nahua. A nivel de la región y para los Sepahuinos en general, los Nahua representan - -y lo han sido por muchos años- el polo simbólico del salvaje, en oposición a ciudades como Atalaya y Pucallpa. Sepahua ocupa en esta perspectiva el punto medio: no es una Comunidad Nativa puramente, ni tampoco sólo un pueblo de colonizadores, ni sólamente una misión católica, ni exclusivamente enclave del capital transnacional. Es todo eso, pero no es una sociedad de cazadores horticultores y habitantes de cabeceras. Al interior de Sepahua y como en una "caja china", se reitera esta visión: el polo del salvaje lo ocupan los propios Yaminahua en oposición a los mestizos, a los Piros y más tenuamente a los Amahuacas. Cabe aclarar que estamos tratando sobre representaciones categoriales y no de grupos étnicos como usualmente se entiende en la literatura etnológica y cuya definición es un espinoso problema.

El jefe Yaminahua de Sepahua en su calidad de intermediario ha asumido frente a los Nahua los roles de civilizador y pacificador. Entre otras cosas, les ha dicho a los Nahua que no usen sus arcos y flechas para cazar, buscando eliminar esos 'objetos-signo' con miras a la constitución de una imagen pacífica de los Nahua. Hay que señalar que goza de una gran receptividad, le tienen un franco afecto y han demostrado estar dispuestos a seguir sus consejos. Para explicar esta reacción necesitamos acercarnos al modo en que los Nahua podrian interpretar el status del jefe Yaminahua. El jefe Yaminahua además de ejercer ese cargo tradicional, es también el chamán de su comunidad. Entre los Nahua contactados, hay dos individuos que detentan esos cargos. En cambio él concentra estos dos roles especializados, que se manifiestan especialmente en obsequios de carne de monte (ie. generosidad material) y en curaciones nocturnas y chamánicas (ei. generosidad espiritual). En nuestra visita encontramos 40 Nahuas viviendo durante varios días en el campamento del jefe Yaminahua en el Alto Mishagua, mientras eran curados y alimentados por él (4), Como líder, su palabra es escuchada y despierta expectativas.

Sumado a su desempeño tradicional, los roles de civilizador y pacificador lo colocan en una posición destacada en el establecimiento de relaciones más permanentes con la región. Roles que se añaden a su jefatura y que ponen parcialmente en cues- 
tión la afirmación de que la actitud etnocida es exclusiva de Occidente (Clastres, 1981). Sin embargo, aquí se trata de un etnocidio particular, pues no es el conocido enfrentamiento de sociedades cuyas respectivas escalas y organizaciones sociales son clara y abismalmente diferentes, sino el de un conjunto regional muy variado y complejo, pero en el que los Yaminahua ya incorporados a occidente, desempeñan un rol cultural de bisagra con los hasta hace poco autónomos Nahua. Al menos en concepción, la estrategia del jefe Yaminahua se expresa muy concretamente en lo que dijo en repetidas ocasiones: "Los Nahua van a ser como nosotros", Sin haber en este deseo eliminación del otro y suplantacion por lo mismo, hay sin embargo, reducción de lo "salvaje" a lo "civilizado" Yaminahua. Los Yaminahua desearían (y en esto son realistas) ver convertidos a los Nahua en Yaminahuas vinculados al mercado, sedentarios, vistiendo ropas, tomando cerveza, trabajando madera consumiendo bienes manufacturados y sin embargo, seguir siendo Yaminahuas. Para contribuir con esta penosa transformación, el jefe Yaminahua trata de introducir la idea del trabajo asalariado (o al menos malamente recompensado con mercancías) y busca convencer a los Nahua para que cambien de apariencia. Los Yaminahua también están conceptualmente entrampados en la oposición civilización salvajismo, que empaña las relaciones entre individuos de los diversos grupos socio-culturales en la región, y entre estos y las instituciones de la sociedad nacional ahí presentes. Oposición que está en la base de toda actitud paternalista integracionista y humanitarista, secular y religiosa, indigenista o eclesiástica. La historia pues se repite aunque con matices, así como en la época del caucho (1880-1920), los grupos ribereños Arawak, enganchados por sus patrones, trataron de someter a las sociedades Pano de las zonas interfluviales (Zarzar, 1983); hoy en día los Yaminahua tratan de contribuir con la integración de uno de los últimos resistentes a la sociedad nacional peruana.

\section{ACTIVIDADES DE SUBSISTENCIA Y CULTURA MATERIAL ENTRE LOS NAHUA}

Los Nahua son habitantes interfluviales que fueron empujados hacia las cabeceras de los pequeños tributarios del río Urubamba (probablemente provenientes de los afluentes del río Purús y quizá antes del Embira, ya en Brasil); gente del bosque más orientada a practicar la cacería que la pesca, y la agricultura itinerante de roza y quema (5). La recolección de frutos y pequeños animales, es parte de sus medios de subsistencia, al igual que los materiales del bosque para la construcción de casas, armas, embarcaciones rústicas y ornamentos de uso cotidiano y-ritual.

Para cazar y pescar sólo han usado arcos y flechas. Entre sus cultivos destacan el plátano, el maíz -incluso el morado-, la yuca, la papaya, el algodón y el tabaco para masticar. También domestican papagayos con cuyas plumas confeccionan coronas.

Su alimentación consiste en carne de monte y pescados cocidos, yuca, maíz asado, y chicha de maíz; desconocían el masato o cerveza de yuca. 
Entre las escasas herramientas encontradas se cuentan una vieja y gastada hacha de metal con la cual uno de los líderes fabricó un par de machetes presumiblemente utilizando restos de metal de los antiguos campamentos caucheros. Su cerámica y cestería es rústica y sin decoraciones. Producen hamacas de algodón trenzado y faldas tejidas de algodón, así como penachos de corteza de uso masculino.

El cuerpo es el centro de sus atenciones estéticas. Entre sus ornamentos destacan las coronas de plumas de diversas aves, como las usadas por los Cashinahua; los cinturones y collares de dientes de mono masculino y femenino; los collares de semillas que las mujeres llevan cruzadas en el pecho. Hombres y mujeres usan narigueras de metal y chaquiras recién adquiridas, en el rostro. Practican la tonsura y se pintan el cerquillo con achiote al igual que todo el cuerpo ocasionalmente; se depilan las cejas y todo el vello del cuerpo y practican bellos diseños sobre la cara, brazos y piernas con guito.

\section{PATRONES DE ASENTAMIENTO Y ORGANIZACION SOCIAL ENTRE LOS PANO Y LOS NAHUA}

La información respecto a los Nahua es aún bastante incompleta. La población total Nahua se calcula en alrededor de 300 personas, repartidas en seis o siete pequeñas aldeas, distribuidas cerca a las quebradas que forman las cabeceras de los ríos Alto Mishagua y Alto Manu: zona de colinas que forma la línea divisoria de las cuencas del Madre de Dios y Urubamba cercana al renombrado istmo Fitzcarrald y límite occidental del Parque Nacional del Manu (véase Mapa No. 3). Las aldeas están a ambos lados de la línea divisoria y su locasión es variable. Están conformadas por unas pocas casas rodeadas de chacras que a su vez se encuentran circundadas por el bosque y las quebradas. Las distancias entre las aldeas varían de medio día a un día de caminata. Algunas casas son multifamiliares, pequeñas malocas casi siempre acompañadas de una o dos viviendas unifamiliares. La variación en el número de viviendas puede deberse al ciclo de desarrollo del grupo doméstico. Dependiendo de la etapa de desarrollo en que se encuentra la familia extensa y de las necesidades matrimoniales y de residencia, podrán haber entre una y tres casas. Cada aldea alberga aproximadamente entre 32 y 48 habitantes. Las casas están construídas por un techo a dos aguas, cuyo travesaño central se encuentra a $3.5 \mathrm{mts}$. de altura y carecen de piso o 'emponado', pero tienen un cielo raso para almacenar maíz. Las familias se distribuyen en hamacas bajo las cuales colocan un pequeño fogón durante las noches. Este mismo fuego es utilizado también para cocinar y asar.

Los Nahua comparten con los otros grupos Pano de tierra firme características comunes, no sólo en relación a sus patracomunitarias, sino también —aunque con variaciones - sus matrimonios y de liderazgo. Hacer una descripción etnográfica de todo ello es imposible ahora. Gran parte de lo que puedo decir debe tomarse como 
hipótesis de trabajo, elaboradas a partir de los pocos datos recopilados y de la lectura de etnografías realizadas entre otros grupos afines a los Nahua.

Podemos decir que en términos tradicionales ideales y de manera muy esquemática, la estructura que ordena las relaciones sociales al interior de la aldea y de la maloca entre los Cashinahua, los Sharanahua y los Yaminahua, era el intercambio de hermanas entre los hombres bajo la forma de matrimonio entre primos cruzados pertenecientes a mitades exógamas (Kensinger, 1976 - Kramer, 1975 - Townsley, 1983). La estructura subyacente al sistema de parentesco estaba compuesta por dos grupos de descendencia patrilineal que realizaban el intercambio de mujeres. Así, nombres como Sharanahua, Yaminahua, Marinahua y otros, habrian designado a grupos de descendencia exógamos.

Según Siskind (1973), cuando estos grupos lograron un crecimiento natural sostenido, la preferencia por casarse al interior de la maloca llevó a que la exogamia fuera siendo desplazada y reemplazada por la endogamia. Estos nombres empezaron entonces a designar a algo más que a grupos de descendencia; se trataba ya de grupos territoriales endógamos, patrilineales y autónomos; unidades socio-políticas autoreproductivas. Con el ingreso de estas poblaciones a la violenta historia regional y el subsiguiente quiebre del asentamiento en torno a las malocas en el periodo cauchero, el movimiento que llevó de la exogamia primigenia a la endogamia, sufrió un proceso inverso desestructurando las aldeas, por lo que en la actualidad encontramos en un mismo poblado mayoritariamente Sharanahua o mayoritariamente Yaminahua; individuos y familias pertenecientes a otros grupos Nahua conviviendo en relaciones de alianzas y afinidad. La desaparición de las malocas llevó al establecimiento de nuevas formas de residencia, en las que destaca una tendencia hacia la matrilocalidad. Así, entre los Sharanahua, la familia matrilocal es el bloque básico de la sociedad, siendo las relaciones entre suegros y yernos las más importantes. Entre los Yaminahua del río Huacapishtea se menciona un patrón de residencia de casas agrupadas por familias que han intercambiado hermanas, siendo las relaciones entre cuñados las más importantes (Kramer, 1975). Entre los Yaminahua de Sepahua la residencia es matrilocal y neolocal: el marido viene a residir en la comunidad de la esposa, pero en casa propia (Zarzar, 1977-78). Entre los Cashinahua la aldea ideal y que no existe tal cual en la realidad empírica, consiste de dos hombres que son dobles primos cruzados y que han intercambiado hermanas; sus hijos, que han intercambiado hermanas y que viven con sus suegros (Kensinger, 1976). Cada hombre y mujer Cashinahua pertenece a una de dos mitades exógamas por cada sexo, mientras que entre los Yaminahua las mitades son dos y no cuatro.

Así, aislando dos rasgos formales más generales del parentesco y la alianza, podemos decir que estos grupos se caracterizan por tener una descendencia patrilineal, residencia matrilocal, matrimonios monógamos y poliginia sororal entre primos cruzados. Tales normas son parcialmente compartidas por los nuevos Nahua. Una aldea Nahua estaría compuesta por mitades exógamas patrilineales que llevan a cabo intercambios monógamos y poligínicos entre primos cruzados al interior de la maloca y de la aldea, por tanto con tendencia a la endogamia y con infrecuentes matrimonios 
entre aldeas que implicarian una residencia matrilocal. Durante nuestra estadía pudimos, apreciar evidente tensión en el encuentro entre individuos pertenecientes a diferentes aldeas, incluyendo las consabidas acusaciones de brujería: un indicador de la endogamia a nivel de la aldea. Los Nahua representarían así uno de los últimos microcosmos sociales Pano, poco afectados en su estructura parental por la historia del avance cauchero.

Un estudio detallado del parentesco Nahua significaría una contribución importante en la comprensión de la organización social de los Pano de tierra firme. Ellos son reflejo del pasado inmediato de todos los Pano del bosque: 'antepasados coetáneos', tradición viva de su historia y su presente alterno más auténtico.

Un dato que llamó nuestra atención, mencionado por los Yaminahua de Sepahua y por los miembros del ILV, fue la supuesta existencia de los líderes en la población Nahua que se había trasladado al puesto del ILV en el Alto Mishagua. Estos eran designados como 'curacas', término ajeno a las características tradicionales de los jefes amazónicos, históricamente impuesto por quienes han penetrado la región desde épocas coloniales y prestado de la estructura política Andina pre-hispánica. Se señalaba la existencia de un 'curaca' viejo y otro joven. El viejo es el padre del joven. El líder entre los Nahua, es el jefe de la maloca, el hombre mayor de una mitad exogámica y cabeza local del grupo de descendencia. El 'curaca' joven resultó ser en realidad un chamán, prestigiado por sus habilidades como cantor y bailarín. Una organización de roles especializados más sofisticada ha sido estudiada entre los Barasana de la Amazonía Colombiana (Hugh-Jones, 1976). En un nivel categorial y no necesariamente en la realidad empírica existen ahí hasta cinco roles: el jefe y el sirviente en el dominio político social, el chamán y el cantor en la esfera ritual, y el guerrero, cuya función está dirigida al exterior en su confrontación con otros grupos exógamos que son fuente de mujeres.

Entre los Nahua hay lo que podríamos llamar una suerte de 'condensación' de ese sistema. Los llamados 'curacas' representan dos poderes, entre los cuales se puede establecer analíticamente analogías y oposiciones que los constituyen como roles complementarios. Un poder político-social o secular, abierto, consensual, visible, que se ejerce en el día, encarnado en el viejo jefe de maloca. De manera opuesta, un poder espiritual-sobrenatural o místico, cerrado, hermético, invisible, que se ejerce en la noche, encarnado por el joven chamán. Siguiendo las características generales del liderazgo en la Amazonía (Clastres, 1974 y 1981), podemos decir que el primero encarna un poder emanado de la sociedad, heredero de la ley y de los ancestros, recipiente del conocimiento secular; el segundo es un poder emanado del mundo sobrenatural, de la comunidad de los espíritus, heredero y recipiente del conocimiento esotérico. El liderazgo del jefe se caracteriza por su generosidad material, manifiesta en obsequios de carne de monte y productos de la chacra. En esta función el joven chamán ha empezado a reemplazar a su padre, dada la avanzada edad de este último; aunque sigue siendo parcialmente el representante del grupo en las relaciones extracomunitarias. La oratoria, una forma de generosidad verbal cuya concreción son los discursos a la vez míticos y étnicos (textos de la ley, cartas morales de la socie- 
dad); tienen como función crucial la persuación, única estrategia para solucionar conflictos y evitar fisiones que atentarían tanto contra la permanencia del grupo, como del cargo del jefe político.

Paralelamente, el liderazgo del chamán se caracteriza por su generosidad espiritual: es el que cura, es decir, el que restaura el bienestar y controla los alucinógenos, comida espiritual. De manera semejante a la capacidad persuasiva del líder político, el chamán requiere de un poder de evocacion manifiesto por el canto, la danza y los encantamientos con los que busca convencer al paciente de su recuperación y de cuya eficacia depende su éxito y el prestigio de su rol. Ambos roles se relacionan con el mundo externo al grupo social. En el caso del jefe, es el mundo de los otros hombres y/o criaturas pseudo-humanas, con la otredad a-social; en el caso de chamán se trata del mundo externo conformado por la comunidad de los espíritus, criaturas pseudo-humanas, habitantes del bosque. Los dos roles comparten los atributos del guerrero: el líder político dirige el enfrentamiento con el enemigo y establece las alianzas con el amigo. El chamán controla y se enfrenta con los espíritus de otros chamanes o de otra gente, y al vencerlos logra sanar o liberar el espíritu de su paciente.

En ambos casos, el liderazgo tiene un límite en la fuente de la cual se obtiene: su prestigio depende de la sociedad de los hombres y de sus concepciones fantasmagóricas o comunidad de espíritus; siendo los primeros, los verdaderos depositarios de un poder que no ha sido alienado del cuerpo social ni del mundo de sus representaciones místicas. Así, la confusión que se produce al designar a estos dos especialistas como 'curacas', tiene como fondo el carácter complementario de sus roles, fundado en performances opuestas con similares atributos.

Sobre otros aspectos de la vida ritual, es muy poco lo que podemos decir. Sabemos que en sus ritos funerarios los deudos se rapan el pelo y entierran a sus muertos en el piso de la casa al son de sus canciones. Cuando las muertes son muy frecuentes, abandonan la vivienda. También pudimos conocer que en la cosecha del maíz llevan a cabo rituales que comprometen a todo el grupo local.

\section{CONSECUENCIAS DEL CONTACTO}

1. De aproximadamente $200 \mathrm{Nahuas}$ que han tenido contacto, la epidemia de gripe ha ocasionado entre 40 y 60 muertes y los ha llevado a una fuerte, aunque eventual, dependencia alimenticia y farmacológica.

2. Han sufrido una prolongada depresión colectiva como resultado de las muertes y de la subestimación cultural de los habitantes de Sepahua.

3. Abandonaron sus aldeas tradicionales debido a dos factores: demasiados muertos y necesidad de apoyo médico. Un sector del grupo se ha reubicado en el puesto 
del ILV (sin reconstruir sus malocas), en dos instancias, antes y después de haber pasado varios meses residiendo en Sepahua. El abandono de la maloca puede significar, además de una reubicación individual y familiar-nuclear, la desaparición del ámbito espacial de la vida ritual y es de hecho, un cambio que afecta radicalmente la vida social cotidiana. Otro sector, el minoritario, ha terminado por instalarse en la Comunidad Yaminahua de Sepahua. Este será, sin duda, el sector que sufrirá mayores y más rápidos cambios socio-culturales y actuará probablemente como intermediario entre los madereros de Sepahua y el río Alto Mishagua.

4. La nuclearización y sedentarización de sus asentamientos serán factores cruciales en la transformación de la sociedad Nahua. Cambios que han seguido la totalidad de las sociedades de tierra firme que en el pasado reciente migraron hacia los ríos grandes.

5. En el ámbito de la cultura material - cuya característica más saltante es ser una cultura ligera y descartable, reemplazable siempre por el stok natural del bosque- - se han introducido principalmente herramientas de metal y ropa (que los Nahua guardan en bolsas), habiendo desarrollado una suerte de 'culto' a su capacidad de duración. Así se ha ampliado el stok de biénes escasos que tradicionalmente habría estado circunscrito a los problemas de la cacería.

6. Igualmente importante en sus efectos, será la más que probable insersión de los Nahua que han regresado al río Mishagua, en el trabajo de extracción maderera que actualmente se lleva a cabo en la zona.

7. En el dominio político se ha producido una división entre los que se inclinan por el jefe Yaminahua de Sepahua, los que siguen al ILV y los que permanecen con sus jefes tradicionales en las cabeceras del rio Manu y se mantienen un tanto al margen de este proceso.

8. En términos globales, se ha producido un cambio más profundo, pero menos evidente. Los Nahua están pasando de ser una sociedad en estado de guerra -al igual que los antepasados de los actuales Pano que se enfrentaron y huyeron del avance cauchero- a ser una sociedad vencida. Al aceptar relacionarse con la sociedad nacional han perdido una característica esencial a su ser social y un rasgo atávico de su historia. Hoy todavía se puede ver deambulando por el pueblo de Sepahua a algunos Nahua mendigando comida o haciendo trabajos serviles como acarreo de agua, bultos o recojo de la basura de las casas de los patrones mestizos.

Todavía se está en una etapa en la que algunos efectos pueden ser reversibles, pues este es un proceso que tiene poco tiempo de inicio y no hay aún una situación claramente definida. Su horizonte dependerá de lo que hagan o dejen de hacer las instituciones nacionales o internacionales presentes en la región y de los deseos y formas de respuesta de los Nahua a este reto temible y a la vez fascinante que es interactuar con la sociedad peruana de frontera. 


\section{LOS MEDIOS DE COMUNICACION}

Los acontecimientos narrados al inicio pasaron a la prensa bajo los siguientes titulares "Estalla guerra de la madera", "Matanza de cuarenta Campas de Pucallpa" y "Madereros asesinan a balazos a más de cuarenta nativos de Pucallpa" (todos en El Popular, dos de octubre de 1984).

Al interior, la noticia detallada era excesivamente confusa; en una misma categoría se incluían Piros y Panos (el último término ni siquiera designa a un grupo étnico), se relatan masacres y epidemias, cadáveres que son arrojados al río Sepahua, pero muertos en Pucallpa, etc.

Estas noticias mezcladas con fotos de diversos grupos étnicos, que no corresponden a los Nahua ni a los mencionados por los periódicos, dio la vuelta al mundo, tantó por los medios escritos como por las estaciones de radio. Días después llegó a Lima un cable de Alemania (El Comercio, 6 de octubre de 1984), en el que la 'Sociedad para los Pueblos Amenazados de Gottinga' exige al gobierno peruano una investigación sobre la supuesta masacre.

Semanas después, otro periódico (La República, 28 de octubre de 1984), publica, aunque recortada, una nota de AIDESEP (Asociación Interétnica de Desarrollo de la Selva Peruana), en la que se hacen varias aclaraciones y correcciones sobre estas noticias y se solicita al Ministerio de Agricultura que no otorgue concesiones forestales en la zona colindante al Parque Nacional del Manu.

Desde que la Amazonía deviniera en esa imagen exótica y deformante de un paraíso deshabitado, pero pleno de recursos naturales: "tierra de nadie, vergel de la abundancia", los medios de comunicación con lamentable frecuencia han contribuído con esa visión, añadiendo a veces ingredientes de violencia y sensacionalismo que no hacen sino incrementar al exotismo aunque a costa de convertir "paraísos ilusorios" en "infiernos verdes".

\footnotetext{
* Deseo expresar mi agradecimiento a FOMCIENCIAS (Perú) que ha sostenido, al igual que algunos fondos de la Universidad de Cambridge (Inglaterra), mi trabajo de campo en el Bajo Urubamba. Una versión anterior de este articulo, fue presentado como ponencia en el Simposium "Etnohistoria de la Amazonia", en el 45 Congreso Internacional de Anericanistas (Bogotá, Julio de 1985).

Cabe añadir que el presente articulo forma parte de una investigación más amplia y en curso, sobre etnicidad, y cuyo tema central son las relaciones extracomunales, las entidades sociales y las categorlas étnicas en el pueblo de Sepahua (Bajo Urubamba).
}

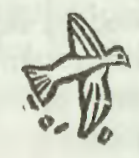




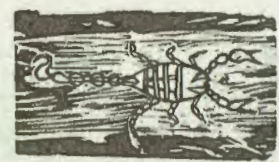

\section{B I B L I O G R A F I A}

\section{CLASTRES, PIERRE}

1977 Society Against the State. Mole Editions. Editions. Oxford.

1981 Investigaciones en Antropologia Política. Editorial Gedisa. Barcelona.

\section{D'ANS, MARCEL}

1972 'Les Tribus Indigenes du Parc National du Manu' en: XXXIX Congreso Internacional de Americanistas, vol. 14, Lima.

1973 'Problemas de Clasificación de Lenguas no Andinas en el Sur Este Peruano'. Documento de Trabajo No. 18. CILA, UNMSM, Lima.

DOUROJEANNI, MARC y

\section{CARLOS F. PONCE}

1978 Parques Nacionales del Perú. Editado por INCARO-CIC, Madrid.

FERRERO, ANDRES, Fr.

1947 Mapa en 'Rutas del Urubamba'. Revista de Misiones Dominicas, año XXVIII, No, 62. Lima.

HUGH.JONES, CHRISTINE

1976 Skin and Soul: The Round and the straight. Social time and social space in Pira-Paraná society. En Actes du XLII Congress International des Americanistes. Vol. II. Paris.

KENSINGER, KENNETH

1976 Cashinahua notions of social time and social space. Actes du XLII ${ }^{e}$ Congress International des Americanistes. Vol. II. Paris.

1983 Investigación Lingǘrtica, folklore y etnografia Pano: retrospección y perspectiva. América Indigena, Vol. XLIII, No. 4. Oct-Dic.
KRAMER, BETTY JO

1975 A look at a Yaminahua Settlement Pattern. Department of Anthropology. Columbia University. Conference on Anthropological Research in Amazo. nia. Queens College, CUNY.

LAS HERAS, JULIAN O.P.

1977 Visita a los Machiguengas del Pakiria y del Alto Mishagua. En: Antisuyo No. 1. Revista de las Misiones Dominicas, Lima.

SCHWARTZ, THEODORE

1981 Cultural totemism: ethnic identity, primitive and modern; en Ethnic Identity: cultural continuities and change. George De vos y Lola Romanucci-Ross (editores). California.

SISKIND, JANET

1973 To Hunt in the Morning. Oxford University Press.

TOWNSEEY, GRAHAM

1983 Apuntes sobre la historia de los Yaminahua en el Perú. En Amazonía Indígena, Af̃o 3, No. 6, Lima.

1986 La sociedad Yaminahua y sus 'otros'. En Extracta No. 5. Lima. Editado por CIPA y Cultural Survival.

ZARZAR, ALONSO

1977.78 Notas de Campo, Sepahua.

1980 "Fronteras de penetración y consecuencias en las etnias del Bajo Urubamba". En Shupihui No. 16, Iquitos, Perú.

1983 Intercambio con el enemigo: etnohis. toria de las relaciones intertribales en el Bajo Urubamba y Alto Ucayali. En Documento No. 5, CIPA, Lima.

DIARIOS:

$\begin{array}{ll}\text { EL POPULAR } & : \text { No. } 16,2-10-84 \\ \text { EL COMERCIO } & : 6 \cdot 10.84 \\ \text { LA REPUBLICA } & : 28 \cdot 10-84\end{array}$

